\title{
Gingival Metastasis Revealing Lung Adenocarcinoma
}

\author{
Lamyae Amro', Leila Maliki'1, Badia Belabidia², Abdelhaq Alaoui Yazidi1 \\ ${ }^{1}$ Pulmonary Departement, Ibn Nafis Hospital, CHU Mohammed VI Laboratory PCIM, FMPM, Cadi Ayyad \\ University, Marrakech, Morocco \\ ${ }^{2}$ Anatomopathology Departement, Ibn Tofail Hospital, CHU Mohammed VI, FMPM, Cadi Ayyad University, \\ Marrakech, Morocco \\ Email: am lamyae@hotmail.com
}

Received 24 January 2014; revised 20 February 2014; accepted 28 February 2014

Copyright (C) 2014 by authors and Scientific Research Publishing Inc.

This work is licensed under the Creative Commons Attribution International License (CC BY).

http://creativecommons.org/licenses/by/4.0/

(c) (i) Open Access

\section{Abstract}

Introduction: The lung adenocarcinoma is an invasive malignant tumor. Its visceral metastases are multiple. The gingival location is uncommon if not exceptional. Observation: We report the case of 66-year-old patient with a right cervical radiculopathology. Clinical examination objectified a superior vena cava syndrome with gingival tumor budding whose excisional biopsy found a location of a poorly differentiated and infiltrating carcinoma. The bronchoscopy revealed a tumor nodule obstructing the right mainstem bronchus with the histological study concluded as a moderately differentiated adenocarcinoma infiltrating. Conclusion: Gingival metastasis revealing lung adenocarcinoma is uncommon even exceptional. It may delay the diagnosis and management of already poor prognosis.

\section{Keywords}

\section{Gingival Metastasis, Lung Cancer, Adenocarcinoma}

\section{Introduction}

Oral metastases are exceptional, representing approximately $1 \%$ of oral tumors. For the soft tissue metastases, the gingival (54\% of cases) and the alveolar mucosa sites are most frequent, followed by the tongue. In $30 \%$ of cases, oral metastasis is the first manifestation of cancer, but it is often a sign of advanced disease with multimetastasis involvement [1]. The hyper vascularization in inflamed periodontal tissues may be a causative factor. The time between the diagnosis of gingival metastasis and death ranges from a few weeks to less than 1 year, with 5 years of maximum survival. We report the case of gingival metastasis revealing the lung adenocarcinoma 
and discuss the diagnostic and therapeutic difficulties associated with the management of the patient.

\section{Case Report}

A 66-years-old mal smoker was admitted to the pulmonary department of chest pain, weight loss, effort dyspnea and fever. Clinical examination objectified a superior vena cava syndrome with gingival tumor budding localized to the upper gum facing the teeth 14 and 15 tender to palpation without bleeding or tooth mobility in contact next strong suggestive of an inflammatory granuloma (Figure 1). The chest radiography objectified a right hilo-apical opacity. Computed tomography (CT) of the lung showed a masse in the right lobe and mediastinal invasion (Figure 2(a), Figure 2(b)). Laboratory tests were normal; the search for BK in sputum was negative. Abdominal ultrasound was normal. The excisional biopsy of the gingival tumor and histopathologic immunohistochemistry suggested a metastasis of lung cancer (Figure 3(a), Figure 3(b)). The bronchoscopic examination revealed a tumor nodule obstructing the right mainstem bronchus with the histological study concluded as a moderately differentiated adenocarcinoma infiltrating.

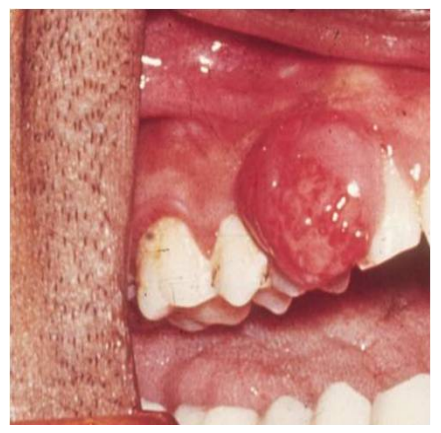

Figure 1. Intraoral view of the gingival tumor.

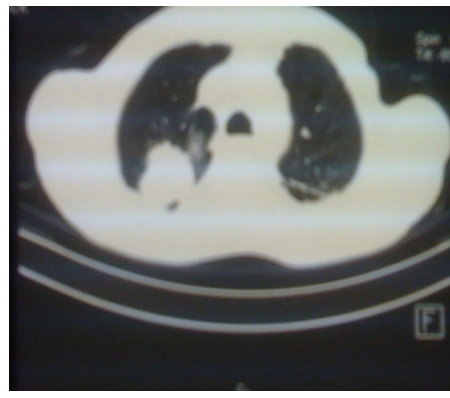

(a)

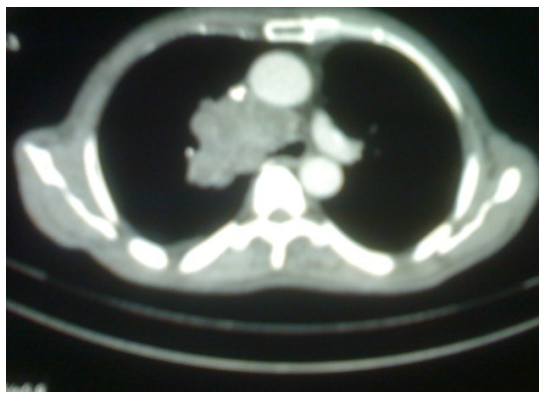

(b)

Figure 2. Tumoral processus in the right lobe and mediastinal invasion.

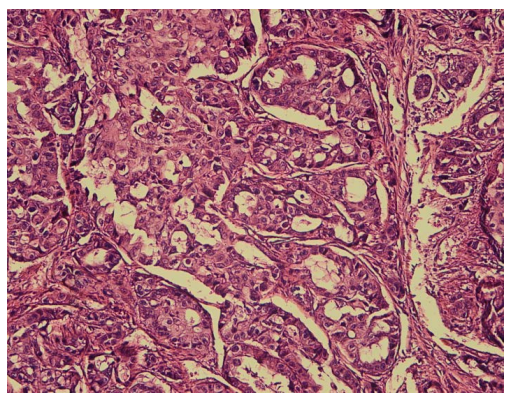

(a)

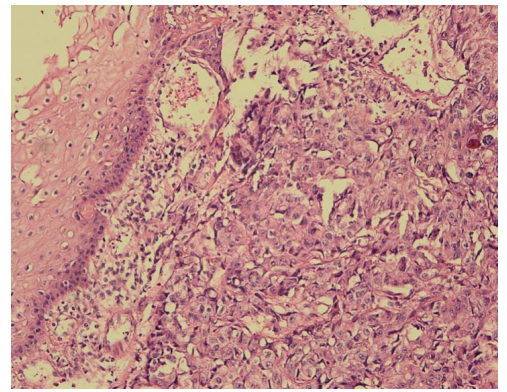

(b)

Figure 3. Moderately differentiated adenocarcinoma infiltrating of gingival localization $(\mathrm{HE} \times 100)$. 
The patient was classified as Stage IV of the OMS classification of lung cancer. In dialogue with oncologists, no additional care was considered because of advanced stage of the pathology and its unfavorable prognosis. The comfort of the patient was maintained by limiting treatment to the simple excision of the lesion and already initiated palliative chemotherapy. Patient died before starting the first course.

\section{Discussion}

Metastatic tumor to the oral region is rare. We report a new case. The objective of our work is to report to whom we were facing difficulties. Two major problems were discussed: Firstly it is a malign tumor or benign? Secondly it is done in a primary or secondary malignancy?

Disease management would be different. Hirshberg et al. [2] reviewed cases of oral metastases reported from 1916 to 1991 and found 157 cases of oral soft tissue metastases, 86 of which had gingival localization. The primary tumors were located in the lung (25.5\%), kidney (15.1\%), bone (10.4\%), breast (9.3\%) and liver (8.1\%). Yoshii et al. evaluated the frequency of the primary pulmonary localizations to be $10 \%$ to $20 \%$ of the cases [3]. The average age of apparence of gingival metastases of pulmonary cancers is 54 years. Our patient was 66 years old. Others authors have emphasized that the prognosis of patients with oral metastases is very poor, with a median survival of less than six months.

Gingival metastases are generally described as polypoid or exophytic, highly vascularized and hemorrhage is very frequently found. One of the principal problems with a gingival metastasis is the clinical distinction between a benign and malign lesion. The final diagnosis is based on histopathologic criteria. The second difficulty is the distinction between a primary tumor and a metastasis. Clinical suspicion must be confirmed by immunohistochemistry. More than 90\% of these tumors have a phenotype CK7+ and CK20-, and the TTF1 expressed by two thirds of the primary adenocarcinoma of the lung [4]. The pathogenesis of oral metastases is poorly elucidated. The local inflammation was the most important factor to attraction of metastatic cells. Their passage in gingival tissues would be facilitated by the greatest permeability of the vessels and the presence of adhesive molecules.

Several studies on the tumor have shown that collagenase and elastases are important mediators associated with the pathogenesis of periodontal disease. Thus, it is possible that concomitant periodontal disease may contribute to the invasion and proliferation of metastatic cells in the attached gingiva.

A metastatic tumor in the gingival is characteristically a rapidly growing proliferative tissue that tends to cause mechanical disturbances, pain and intermittent bleeding from a necrotic and non-healing ulcer. In our patients, no other metastases were found, but unfortunately he died because of unstable respiratory status.

There is no proven treatment for the gingival tumors, and prognosis is very poor. Tanaka et al. [5] reported that the median survival time of lung cancer cases with gingival metastasis was only 4 months.

\section{Conflict of Interest Statement}

The authors declare they have no conflict of interest.

\section{References}

[1] Curien, R., Moizan, H. and Gerard, E. (2007) Gingival Metastasis of a Bronchogenic Adenocarcinoma: Report of a Case. Oral Surgery, Oral Medicine, Oral Pathology, Oral Radiology, and Endodontology, 104, 25-28. http://dx.doi.org/10.1016/j.tripleo.2007.06.021

[2] Orlandi, O., Basso, M., Salvator, M., Federico, F., Cassano, A. and Barone, C. (2011) Lung Adenocarcinoma Presenting as a Solitary Gingival Metastasis: A Case Report. Journal of Medical Case Reports, 202, 1-4.

[3] Yoshii, T., Muraoka, S., Sano, N., et al. (2002) Large Cell Carcinoma of the Lung Metastatic to the Mandibular Gingiva. Journal of Periodontology, 73, 571-574. http://dx.doi.org/10.1902/jop.2002.73.5.571

[4] Watanabe, E., Touge, H., Tikuyasu, H. and Kawasaki, Y. (2008) Gingival Metastasis of Adenocarcinoma from the Lung. Respiratory Medicine, 1, 103-106.

[5] Tanaka, M., Hiraki, A., Ueoka, H., et al. (2002) Gingival Metastasis in Lung Cancer. Oncology Reports, 9, 571-574. 
Scientific Research Publishing (SCIRP) is one of the largest Open Access journal publishers. It is currently publishing more than 200 open access, online, peer-reviewed journals covering a wide range of academic disciplines. SCIRP serves the worldwide academic communities and contributes to the progress and application of science with its publication.

Other selected journals from SCIRP are listed as below. Submit your manuscript to us via either submit@scirp.org or Online Submission Portal.
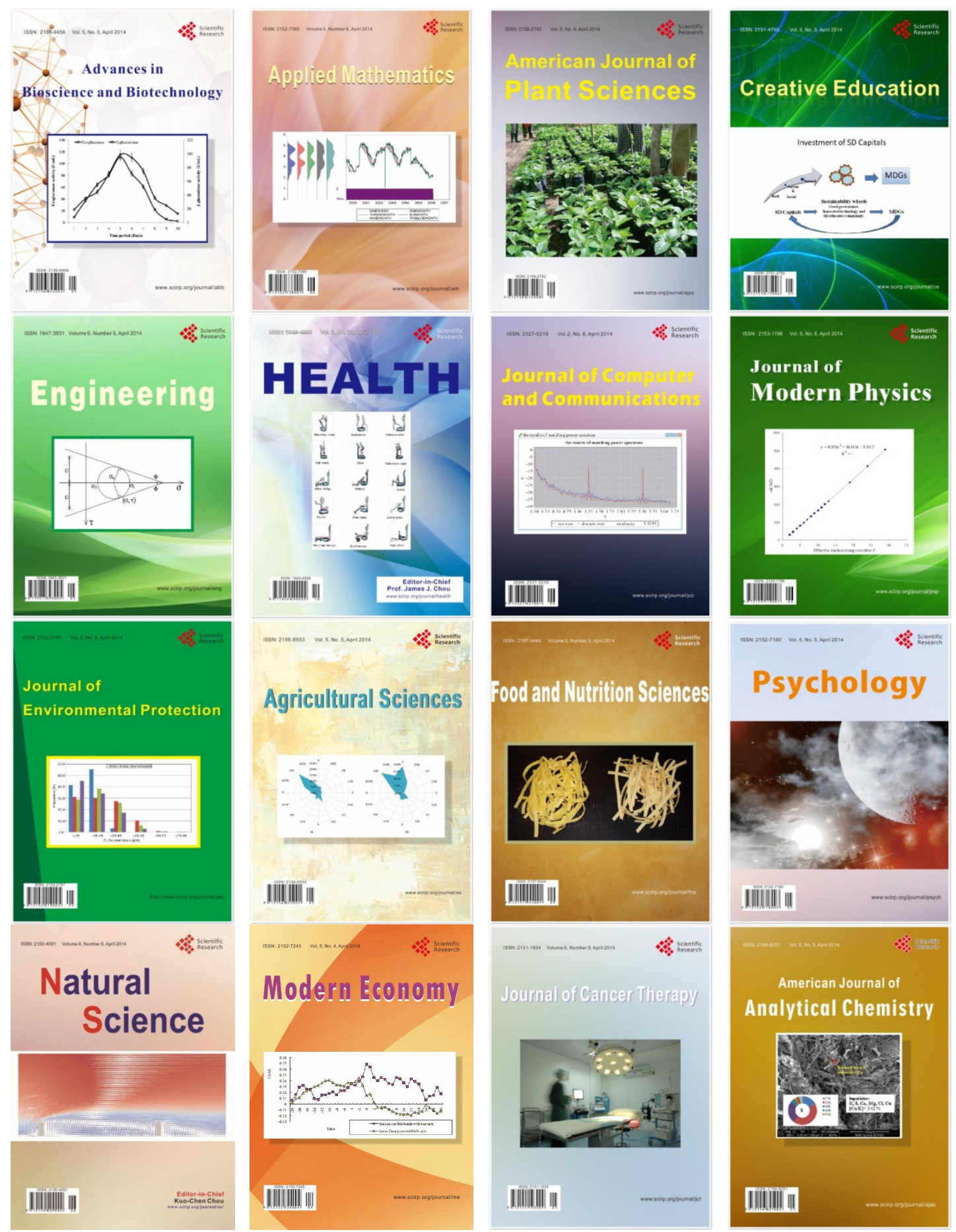